\title{
Research on Current Situation and Development Measures of
}

\section{Qingdao's Sport Industry}

\author{
Yun Ma \\ Physical Education Department, Qingdao University of Science and Technology \\ Qingdao 266042, China \\ E-mail: pemayun@163.com
}

\begin{abstract}
Employing the documentary data method, investigation and logical analysis, this paper aims at learning about current development as well as problems of Qingdao's sport industry and putting forward with some countermeasures and suggestions, hence providing reference for its future development.
\end{abstract}

Keywords: Qingdao, Sport industry, Development, Current situation

As a special cultural phenomenon of human beings, sport has made our life more wonderful with human multiplication. The development degree of sport industry has become a significant standard to measure a nation's economic and cultural development. Currently, globalization of sport industry has promoted it to be a major industry in many countries. Up to now, the world sport output value has reached 500 billion dollars, being called a permanent rising industry with bright prospects. It is estimated by economists that this industry will become one of the four major industries in the $21^{\text {st }}$ century. Starting at the beginning of $1980 \mathrm{~s}$, china's sport industry has achieved rapid development despite its laggard start. Now this industry has become a special industry in the national economic system with its overall plan expanded gradually.

Under such a new situation, it has become urgent to find out current development, to take measures to solve problems and figure out countermeasures in strategies and methods related to Qingdao's sport industry.

\section{Current Development of Qingdao's Sport Industry}

\subsection{Fitness Market Taking the Dominance}

Many scholars have pointed out the greatly improved ideas in sport consumption especially among women. Ever since the popularity of yoga and aerobic exercise in Chinese fitness centers, these sports have satisfied women's purpose of pursuing beauty as well as green health. In almost a hundred fitness centers held in Qingdao, we find through our investigation that they have attracted a lot of customers and even some have opened several branches in the same district within several months, revealing people's enhanced sense of fitness.

\subsection{Growing Competition Demonstration Market}

With the establishment of football club system, improved sport tactics, appearance of commercial competitions as well as fan teams, Qingdao's sport competition market has achieved rapid development. As the cradle of China's yacht sport, Qingdao has the reputation of "Capital of Yacht" due to its blessed water resources and long history of yacht sport. In addition, the yacht races of 2008 Beijing Olympics and the $11^{\text {th }}$ National Games in 2009 were also held here.

\subsection{Rapidly Expanded Sport Facility Market}

Qingdao's sport facility industry is mainly focused on sales, including specialty stores, such as Adidas, Nike, Jordan and some other international name-brands as well as some domestic ones such as LINING, ANTA, Xtep sold in large, medium or even small department stores or specialty stores.

\subsection{Prosperous Paid Physical Training}

Nowadays, paid physical training classes, such as martial arts, aerobics, swimming and physical dancing, are unprecedentedly prosperous. Paid training is beginning to appear in elementary and intermediate training. Some basic sport training classes, such as youth swimming training, have been overcrowded, revealing great market potential in paid physical training.

\subsection{Seriously Laggard Sport Agency Market}

Sport agency market derives from sport core market. As is shown in the development trend of western countries' 
sport industry, the development of sport agency market depends on that of professional sport market. This market in Qingdao has started along with professionalized reform in some items in recent years, with its poor overall development, insufficient demands from a variety of sport markets, a small amount of specialized sport brokerage companies providing only monotonous business and limited influence. In addition, this market is lacking in sufficient management and qualified staff.

\section{Problems in Qingdao's Sport Development}

\subsection{Poor Sense of Sport Industry and Ineffective Policy Measures}

Although the Engel's coefficient of Qingdao urban residents has reached the level of medium-level developed countries and their demands for the improvement of living quality and the development of citizen quality have become a strong drive for sport consumption, people don't attach enough attention to sport industry and sport economy, have poor understanding of sport industry, neglect the purpose and significance of sport consumption, have no overall planning and guidance, have monotonous policies, measures and methods and lack universal ideas and proper methods.

\subsection{Imbalanced Development of Sport Industry}

At present, imbalance exists in the development of Qingdao's sport industry. First, there is imbalance among different regions due to restrictions in society, economy, culture, population, resources, natural environment and ideas. Second, sport industry ownership is imbalanced. As is revealed in our survey, a large proportion of stadiums and gymnasiums are state-owned. Third, there is also imbalanced development among different sports. Due to their different popularity, competitiveness as well as advertising value, different sports will achieve different market degree or profit from industrial development.

\subsection{Poorly-Planned Sport development}

Along with people's raised income and greater demands for fitness, entertainment and recreation, some sports appear incomplete in the investment and introduction process, such as golf, bowling, billiard and fishing, resulting in vicious competition, serious waste of human resources as well as increasingly fierce competition in variety, quality, price and sales of products.

\subsection{Incomplete Sport Structure}

Sport industry is composed of major industries, relevant industries and other industries. Since major industries are controlled by government and have high degree of monotony, their development is quite restricted. Therefore, relevant and other industries should be developed instead to accumulate capital in the initial period.

\subsection{Lacking in High-Quality Professional Talents}

Talents proficient in both sport and economics are called for in the development of sport industry. However, there is only the sport economics major instead of colleges specialized in sport economics in Qingdao, failing to offer sufficient successors for the development of sport industry. In addition, among the existing management staff, their out-of-date knowledge needs to be updated or complemented. Now the lack in management talents has become a key factor restricting the development of Qingdao's sport industry.

\subsection{Insufficient Use of Sport Resources}

Although Qingdao owns a high proportion of sport capital, a part of it has been set aside or used in an inefficient way, especially in those state-owned stadiums which have low utilization rate due to its closure to the public.

\section{Opportunities for the Development of Qingdao's Sport Market}

\subsection{Constantly Improved Resident Income}

Constant and rapid growth of GDP and resident income serves as a precondition and fundamental guarantee for the development of sport market. Basically, sport industry needs to be propelled by economic growth. It is impossible to achieve the development of sport industry and the prosperity of sport market without the constant growth of GDP and improved resident income. Both propel each other with the former as the basis and precondition.

\subsection{A Huge Potential Sport Consumption Group}

By 2000, the total population in Qingdao had reached 7,066,500 and reached 8,386,700 by 2007, with a $2.33 \%$ increase compared with that in 2005 and an annual increase of 1.2\%. Annually, there are 188,000 people added to the list. It is estimated that Qingdao will have around 8,900,000 people by the end of 2010. With an increase in population and household, there will be greater demands for sport consumption. Supposing an average person 
spends 2,000 yuan every year on sport consumption, Qingdao will have 1,780,000,000 yuan worth of sport consumption, which will, of course, have great impact on economic growth.

\subsection{Accelerated Urbanization}

Urbanization is a fundamental way to eliminate the dual structure of urban and rural areas in China as well as a significant symbol of advanced civilization. According to the definition of a well-off society in economics, a well-off society should have an urbanization rate over $40 \%$. However, we still have a long way to go towards this goal. Some measures should be taken, such as increasing the number of cities by reducing the population standard for cities and establishing satellite cities, promoting the diversification of cities, attaching importance to life-oriented cities, especially new cities specialized in tourism, business and transport.

\section{Countermeasures to Develop Qingdao's Sport Industry}

\subsection{Changing Ideas and Laying Down Beneficial Industrial Policies}

Since the development of sport industry is closely related to the reform of sport system, we are expected to have a proper understanding of the goal, content and significance of this reform. In addition, we have to realize the significance of the development of sport industry for that of economic society. Government's critical role should be exerted by establishing and perfecting a series of policies on sport industry.

\subsection{Constantly Cultivating the Idea of Mass Sport Consumption}

The idea of "spending money on health" should be enhanced to promote sport consumption to be an important part in mass consumption. The Olympics and The National Games should be taken advantage of to strengthen people's sport sense and a new theme as well as four new ideas should be established. The theme of "sport creates better life" can be based on to encourage new ideas that fitness is quality, taste, opportunity as well as living quality, hence establishing a healthy, happy and fashionable image and arousing people's diversified and classified sport consumption wishes.

\subsection{Developing Sport Competition Market}

More international and national large-scale games should be held to fully exert the diverse functions of sport competitions on economy and to input new vitality into Qingdao's sport industry. In addition, the marketization of some advantageous sports in Qingdao should be enhanced, especially yacht, football, basketball and other sports with popular mass base and national advantages.

\subsection{Actively Cultivating Fitness Entertainment Market}

Greater efforts should be made to guide and encourage establishing all kinds of fitness clubs, developing high-level clubs to provide places, facilities and guidance for people's sport activities as well as to satisfy consumers' demands for sport at different levels. In operation, advantages in traditional sports as well as modern ones can be exerted and some exciting foreign facilities and sport games should be introduced actively.

\subsection{Standardizing Sport Agencies and Establishing Relevant Self-Discipline Organizations}

Generally, sport resources are allocated by agencies. However, since China's sport management system is lying in the transition period to market economy, this industry has not mature marketization, restricting the development of brokers. Although there are some transactions in this field nowadays, no real sport labor market or technology market has been formed. For instance, the transfer of players and the spread of games are all conducted in a kind of disorder without a high level of brokerage.

\subsection{Enhancing the Cultivation of Talents Specialized in Sport Industry}

Present staff in sport industry should be trained to endow them with more modern economic theories and skills and more skills to develop sport market. Besides, some talents with a good mastery of operation and management should be selected from other economic fields to come to sport industry. Sport colleges are also expected to encourage researches on sport economic management in order to improve the operation and management of sport industry in Qingdao.

\section{References}

Bao, Xiaoming. (2000). Sport Market: A new Economic Growth Point. People's Sport Press, (12): pp 56-60.

Li, Ning. (2002). Current Development and Policy Orientation of China's Sport Industry. Journal of Nanjing Sport College, pp 33-38.

Modern investigation group on China's mass sport. (1998). Modern Investigation and Research on China's Mass Sport. Beijing Sport University Press, p 32. 
Wu, Jianchun. (2007). On Current Situation and Development of China's Sport Industry. Journal of Southeast University, pp 85-93.

Yu, Jiying. (2002). Research on China's Industrialized Development Strategies of Sport. China Sport Science and Technology, (3): pp 104-106. 